\title{
LA MATERIA EN ROGERIO MARSTON
}

\author{
Antonio Perez-Estevez
}

SÍNTESE - Dentro da Escola Franciscana dos séculos XIII e XIV, debateu-se muito a respeito da matéria e da forma, bem como da relação entre elas. Rogério Marston, não dos mais conhecidos, também envolve-se neste debate, de procedência aristotélico-árabe, a qual acrescentase a noção cristã de um Deus onipotente, criador da matéria. No presente trabalho mostra-se qual a noção de matéria-prima para Marston, ficando evidente $a$ influência de Aristóteles e a superação de posiçōes anteriores, como as de Boaventura.

\begin{abstract}
In the Franciscan School of the thirteenth an fourteenth centuries matter and form as well as their relation were a subject of exciting debates. Roger Marston, not very known, also participates in this discussion, which proceeds from Aristotelian and Arabic philosophers; he adds the Christian notion of a omnipotent God, creator of the matter. In this article the author shows Marston's notion of materia prima, making clear Aristotle's influence and the superation of former ideas like those of saint Bonaventure.
\end{abstract}

\section{1 - Introducción}

Encontramos a Rogerio Marston, ya franciscano, en la Universidad de Pans entre 1270 y 1272 . No sabemos con precisión qué edad tenia en ese momento, pues mientras unos ubican su fecha de nacimiento en 1235, otros lo hacen en 1250.' Son sus profesores: Juan Pecham, Guillermo de Mara y Estaquio.

Los dos anos pasados en París como estudiante, deben haber sido determinantes en la formación ideológica de Marston. Son años estelares los vividos por la Universidad de París, debido al grupo de destacados profesores que integran su claustro. Tomás de Aquino y Juan Pecham habian llegado casi simultáneamente en los primeros meses de 1269 y van a ser animadores del ambiente académico parisino: Tomás de Aquino, como fundador de la nueva corriente que introducía el Aristotelismo en Teología y Pecham como fundador de la corriente franciscana, que recoge la vieja tradición agustiniana de la Facultad de

Este trabajo es un capitulo de un proyecto más amplio de investigación sobre "La Materia en la Escuela Franciscana en el siglo XIII" que ha sido subvencionado por el Consejo Superior de Investigaciones Cientificas de España (CSIC).

- Universidad del Zulia, Maracaibo - Venezuela.

1 En el Prólogo a las Questiones Disputatae (Qharachi, Florentiae, 1932, p. 8) se da como probable el año de 1235. Fernando Etzkorn, sin embargo, ubica el nacimiento de R. Marston en 1250 (The Encyclopedia of Philosophy, McMillan, New York, 1967, v. 5, p. 168-169). 
Teología. Ambos, como capitanes de dos corrientes ideológicas distintas, dirgirán los conflictos doctrinales que se iniciarán entre dominicos y franciscanos. Contemporáneo de Tomás de Aquino y Juan Pecham, Siger de Brabante dirige la corriente averroísta que traía conmocionada la vida universitaria y que nucleaba un importante número de seguidores.

Dos hechos acaecidos en el otoño de 1268 inciden también en el ambiente universitario que le toca vivir a Rogerio Marston: el nombramiento de Etiènne Tempier como Obispo de Paris el 7 de Octubre de 1268 y la muerte del Papa Clemente IV. Con Tempier, quien venía de ser un destacado Maestro y Canciller de la Universidad, el Obispado de Paris va a estar pendiente de todo el quehacer universitario para intervenir cuando lo juzgue conveniente, especialmente en el interregno papal que corre desde la muerte de Clemente IV el 29 de Septiembre de 1268 hasta la elección de Gregorio X el 1 de Septiembre de 1271. Son casi tres ados en los que el vacio de poder papal invita a libertades doctrinarias que Etiènne de Tempier se ve obligado a vigilar y a condenar. El Decreto del 10 de diciembre de 1270 en el que se condenan, como erróneas, trece proposiciones inspiradas en la filosofia pagana es la prueba fehaciente de que Tempier está dispuesto a intervenir en la Universidad de Paris para evitar desviaciones peligrosas.

Tomás de Aquino llega por última vez a París en Enero de 1269 proveniente de Viterbo, en donde había estado enseñando desde finales de 1267 en la Curia papal. Tomás de Aquino llega y comienza de inmediato a enseñar y a influir de una manera determinante en el mundo académico de la Universidad. De hecho en el primer semestre del mismo ado 1259 sostiene la disputa De Anima y hacia Pascua redacta el Quodlibeto I, mientras a lo largo del aho 1270 comenta la Fisica aristotélica, escribe el segundo, el tercero y el décimo segundo Quodlibetos, juntamente con el De Unitate Intellectus.

Tambien en el aho 1270 ven la luz pública el De Erroribus Philosophiae de Gilles de Roma y el De Intellectu de Siger de Brabante, posiblemente como respuesta al de Tomás de Aquino sobre el mismo tema.

Los dos anos siguientes Tomás de Aquino escribe incansablemente: la Ia Ilae y la Ila Ilae de la Summa Theologica, los Quodlibetos IV, V y VI, el de Aeternitate Mundi, disputa De Virtutibos y De Unione Verbi. Siger de Brabante publica en estos mismos anos Impossibilia, De Necessitate y De Aeteraitate Mundi. Juan Pecham redacta algunas de sus obras más importantes durante su estancia en París: las lecturas de las Sententiae, la mayoria de las Quaestiones Quodlibetales y su Tractatus Pauperis.

Como podemos darnos cuenta por esta rápida ojeada, la vida universitaria que presenció Rogerio Marston en sus dos años parisinos estuvo llena de hechos significativos y de enfrentamientos doctrinales, que marcarán sin duda su pensarniento y su vida. Discípulo de Juan Pecham y de Guillermo de Mara, Rogerio Marston vive las agrias disputas entre la Escuela Franciscana y la corriente Tomista. Resonancias de estas luchas doctrinales, las encontramos en los escritos y en las ideas de Marston, aunque ya estén mitigadas por los años transcurridos y por la madurez del Profesor de Oxford. 
En efecto, entre 1281 y 1284 se desempeña como profesor de Teología de la Universidad Oxoniense, siguiendo una glọiosa tradición franciscana que se habia iniciado en el mismo momento de la llegada de los Hermanos Menores en 1224 y la creación de su Studium a partir de 1230. Adam Marsh, Geoffrey d'Aspall, Thomas de York, Richard Rutus - sin citar a Roger Bacon - lo habían precedido en una secuencia de profesores ilustres, apenas estudiados hasta hoy, y cuyo origen se remontaba al multifacético Roberto de Grossetesta, pues, si bien él no fue franciscano, organizó, sin embargo, el Studium Generale de los Menores en Oxford entre los años 1230 y 1235.

Los escritos de que disponemos: Quaestiones Disputatae (Quarachi, Florentiae, 1932) y Quodlibeta Quatuor (Quarachi, Florentise, editio 2a, 1994) pertenecen a esta época de docente en Oxtord. Probablemente las "Quaestiones disputatae de anima", las que a nosotros más nos van a interesar, fueron redactadas a finales de 1283, mientras que los dos primeros "Quodlibeta" pertenecen el primero al año 1282 antes de la Navidad y el segundo al inicio de 1283. El tercero parece haber sido redactado en la Navidad de 1283. El cuarto es su última obra conservada y parece haber sido escrita en Cuaresma de $1284 .^{2}$

La bibliografia sobre Marston no es abundante. Sobre su filosofia natural conozco un trabajo importante de Etzkorn Ferdinand, "The Grades of the Form according to Roger Marston OFM", Franziskanische Studien, 1962, 44, p.418-455, al que haré frecuentes menciones.

\section{2 - El concepto de materia prima}

\section{1 - La materia prima una entidad absoluta}

La materia tiene, para Marston, un doble sentido, a saber: o bien se entiende por materia la corporeidad con sus accidentes tal como la percibimos por los sentidos, o bien como parte constitutiva del compuesto entendida sólo por el entendimiento. ${ }^{3}$ La materia, entendida como cuerpo extenso, concreto con sus accidentes, la percibimos por los sentidos externos; a esta materia perceptible, es decir, al cuerpo extenso concreto con todos los accidentes que percibimos por los sentidos, la denomina también apéndices materiales o accidentales y no le dedica apenas atención. La materia inteligible y entendida sólo por el entendimiento, es decir, la materia como parte constitutiva del compuesto, sin la forma de corporeidad y sin accidente alguno, va por el contrario a ser objeto de numerosas páginas en distintas ocasiones. Es de advertir que ambas materias, la inteligible y la sensible, se dan en la realidad, aunque para conocerlas tengamos que utilizar distintas facultades cognoscitivas. La materia sensible la descobrimos en los cuerpos extensos por medio de los sentidos externos v.g. vista, oído, tacto... La

Etzkorn Gerardus, "Prolegomena”, Rogeri Marston Quodlibeta quatuor, Grottaferrata, 1994, p. 69*.

De Anima, q. II, p. 232: "nam, cum dicit in primis quod 'materia individualis est causa singularitatis' necesse est hoc intelligi, ut videtur, de materia quae est altera pars compositi [...] Quando, igitur, dicunt philosophi quod abstractio fit a materia, non est intelligendum quod haec fit a materia quae est altera pars compositi, sed materiam vocant corporeitatem et alia accidentia, quibus res a sensu aprehenditur." 
materia inteligible es también real, pero captable sólo por el entendimiento; debajo de la corporeidad extensa con accidentes, se oculta la materia inteligible como parte del compuesto sustancial sobre la que se da la extensión y los demás accidentes. Detengámonos por tanto con atención en el análisis de esta materia inteligible o parte constitutiva del compuesto.

La primera característica de esta materia es su entidad absolta. E1 ser de la materia para Marston es un ser absoluto de igual manera que lo es el ser de la forma. Y ser absoluto significa que la materia tiene una esencia y un ser en acto, distintas de la forma." En la tradición aristotélicotomista la materia ni tenía propiamente esencia ni mucho menos existencia propia. Su entidad misteriosa que no era, pero tampoco era nada, consistía en ser potencia o estar en disposición de recibir formas. Pero Rogerio Marston añade que la materia, justamente por tener esencia propia, debe tener su propio acto de ser, debido a que el ser depende de la esencia y la sigue. En consecuencia, la materia, como parte del compuesto, posee, igual que la forma, una esencia y un ser propios que la hacen ser una realidad absoluta tan absoluta como la forma. El compuesto, indivíduo existente, será la unión de dos realidades absolutas, ambas con su esencia y su ser."

Pero ¿qué tipo de ser es éste del que nos habla Marston con respecto a la materia en cuanto posee una esencia distinta de la forma? Ferdinand Etzkorn entiende que "el ser de la esencia o quididad puede ser aislado por medio de la definición. Este 'ser' esencial nada tiene que ver con la actualidad de existir o noexistir. Al esse en su perspectiva como quididad definible, en cuanto imita a su idea en la mente de Dios, se le llama esse essentiae y como tal depende y sigue a la esencia a la que pertenece". "Esto va a ser aplicado a la materia en cuanto esencia distinta de la forma y nada va a decir Etzkorn de la consistencia ontológica que entraña "el ser propio inherente inmediatamente a la esencia de la materia". Los textos, sin embargo, de Marston parecen expresar que la esencia de la materia en sí misma posee un 'ser en acto' propio e inherente a la materia y que no puede ser reducido y aislado en el simple plano de la definición. Vamos a intentar determinar 'este ser propio de la esencia'a través de algunos textos.

Veamos el primero de Quodlibet I, q. II, p 10 y 11. En esta cuestión se plantea Marston si Dios puede hacer que la materia exista en acto sin la forma. Va a enfrentar la posición de Tomás de Aquino, al que Marston cita textualmente (Tomás de Aquino, Quaestiones Disputatae, Quodlibet III, q. I) y quien sostiene que Dios no puede conservar la materia, sin la forma, porque hacer esto implica contradicción. La argumentación del Aquinate es la siguiente:

1 Quodlibet I, q. II, p. 10, 4a: “[...] cum essentia materiae sit alia ab essentia formae, impossibile videtur quod esse inmediate inhaerens essentiae materiae sit ipsa forma. Nam esse cuiuscumque essentiae ab ipsa essentia cuius est dependet et ipsam consequitur."

- Quodlibet I, q. XIII, p.33, 3: "materia est susbstantia et est essentia [...] substantia dicitur in quantum substat formae, essentia in quantum est res absoluta."

5 Etzkorn, Ferdinand, "The Grades of the Form according to Roger Marston OFM", Franziskanische Studien, 1962, n. 44, p. 420: 'the essence corresponding to the essence whereby the 'whatness' of a being can be isolated by definition. A definition, says Marston, indicates quiddity and does not concern itself with the actuality of existing or non-existing [...] Esse in its perspective as a definible quiddity, as imitating its idea in the mind of God, is called esse essentiae and as such depends and follows upon the essence ot which it 'belongs'." 
"Todo lo que es en-acto, o es él mismo acto o potencia que participa en el acto; ser en acto repugna a la razón de materia, cuya esencia propia es ser-enpotencia. Por tanto, tendrá que participar de un acto. El acto de ser participado de la materia no es otro que la forma; de aqui que es lo mismo decir que la materia es en acto y (decir) que la materia tiene forma. Decir que la materia es en acto sin la forma, es decir algo contradictorio". A este argumento tomista, responde Marston diciendo que, aunque probable, es deficiente y equivoco o, incluso, contiene falsedad. Acepta el argumento hasta la proposición 'el acto de ser participado de la materia no es otro que la forma'. Señala que, para Tomás de Aquino, el acto mismo de existir de la materia es la forma misma.

Y pasa a argumentar por su cuenta:

\begin{abstract}
"Esto parece falso porque, aunque la materia tenga el ser a partir de la forma por el hecho de que la forma da el ser a la materia, sin embargo, como la esencia de la materia es distinta de la esencia de la forma, parece imposible que el ser inmediato inherente a la esencia de la materia sea la forma. Pues el ser de cada esencia, de ella depende y la sigue. Por tanto, si la forma fuese el acto mismo de existir de la materia, dependeria totalmente de élla y la seguiria como una pasión propia"."
\end{abstract}

Descompogamos en proposiciones todo el párrafo:

1. La proposición: 'El acto de ser en el que la materia participa no es otro que la forma'es falsa.

2. La materia tiene el ser a partir de la forma por el hecho de que la forma da el ser a la materia.

3. La esencia de la materia es distinta de la esencia de la forma.

4. Parece imposible que el ser inmediato inherente a la esencia de la materia sea la forma, pues el ser de cada esencia de ella depende y a ella sigue.

5. Por tanto, si la forma fuese el acto mismo de existir de la materia, ésta dependeria totalmente de aquélla y la seguiría como una pasión propia".

La forma es, según el Aquinate, el acto de existir de la materia. A Marston, por el contrario, le parece imposible que el ser inmediato inherente a la esencia de la materia sea la forma, pues en ese caso la seguiria como una pasión o accidente. Este ser inmediato e inherente a la esencia de la materia, parece conotar el acto de existir de la materia, tal como repite en el argumento varias veces, acto de existir que no es la forma misma.

Un segundo argumento va a dar Marston, para negar que la opinión tomista de que la forma sea el acto de existir de la materia, explicando la múltiple significación equivoca de 'acto':

"En este argumento se utiliza acto equivocamente. Pues acto, en un primer sentido, es sinónimo de forma o perfección, como cuando decimos 'el alma es acto del cuerpo'. En un segundo sentido, es lo mismo que acción u operación. Y en un tercer sentido equivale a actualidad, que es la propiedad de ser, como cuando decimos que una cosa es en-acto,

\footnotetext{
Quodlibet I, q. II, p. 10, 4, a: "Hoc enim videtur falsum quia, licet materia esse habeat a forma, eo quod forma dat esse materiae, tamen, cum essentia materiae sit alia ab essentia formae, impossibile videtur quod esse immediate inhaerens essentiae materiae sit ipsa forma. Nam esse cuiuscumque essentiae ab ipsa materia cuius est dependet et ipsam consequitur. Si ergo forma esset ipse actus exsistendi materiae, ab ipsa materia totaliter dependeret et ipsam consequeretur tanquam ei propria passio."
} 
esto es, en su actualidad. Cuando se dice que la forma es acto de la materia, se entiende en el primer sentido. En el argumento, sin embargo, se toma ser en el tercer sentido."

Descompongamos el párrafo en proposiciones:

1. Acto es un término equívoco y tiene tres sentidos.

2. En un primer sentido, acto es sinónimo de forma o perfección v.g. el alma es acto del cuerpo.

3. En un segundo sentido, acto es lo mismo que acción u operación.

4. En un tercer sentido, acto es lo mismo que actualidad v.g. una cosa es en-acto o en su actualidad.

5. Cuando decimos que la forma es acto de la materia, se entiende como perfección (no como actualidad o ser en acto).

6. Tomás de Aquino, en su argumento, lo entiende como ser en-acto, como actualidad de ser. En este argumento, resumiendo, Marston insiste que la forma no es el acto de existir de la materia, tal como afirma Tomás de Aquino, sino que, cuando decimos que la forma es acto de la materia, ha de entenderse que la forma perfecciona a la materia.

Un tercer argumento utiliza Marston en contra de Tomás de Aquino:

\begin{abstract}
"[Dios] puede producir inmediatamente y per se todo efecto, producido por medio de una creatura. Asi, como da el ser a la materia mediante la forma, puede donar ese mismo ser, en cuanto que el ser es una propiedad del ser de la materia misma. Como el ser sigue inmediatamente a la esencia, si Dios por si mismo mantuviese la esencia de la materia, que tuvo el existir por medio de la forma, se seguiria necesariamente que [la materia] recibe de Dios el mismo ser que recibia de la forma"."
\end{abstract}

Descompongamos en proposiciones:

1. Dios puede producir inmediatamente y per se todo efecto, producido por medio de una creatura.

2. Dios da el ser a la materia mediante la forma; puede Dios inmediatamente y per se donar ese mismo ser a la Materia.

3. El ser sigue inmediatamente a la esencia; Dios puede mantener la esencia de la materia, esencia que tuvo el existir por la forma.

4. Se sigue necesariamente que recibe de Dios el mismo ser que recibió de la forma.

Queda claro en este argumento que, en el estado actual de cosas, la materia recibe el acto de existir de Dios por medio de la forma, mediante forma. Pero, en

Op. cit., p. 11, 4, b: "Unde in isto processu est aequivocatio de actu. Nam actus uno modo est synonymum cum forma vel perfectione, secundum quod dicimus 'anima est actus corporis' alio modo idem est quod actio vel operatio; tertio modo idem est quod actualitas, quae est proprietas essendi, secundum quod dicimus quod res est actu, id est actualitate sua. Quando igitur dicit quod forma est actus materiae, actus primo modo sumitur; ipse vero in processu accipit esse tertio modo."

- Op. cit., p. 11, 5: "Potest (Deus) ergo immediate per se in omnem effectum in quem potest mediante creatura. Et ita, cum det esse materiae mediante forma, potest illud idem esse, secundum quod esse est proprietas essendi ipsius materiae, tribuere, quamvis hoc aliqui non concedant. Si enim ad essentiam immediate consequitur esse, si Deus per se ipsum manuteneret essentiam materiae, quae per formam habuit exsistere, sequitur necessario quod idem esse habet a Deo quod habuit a forma." 
otro estado de cosas, Dios puede donar a la materia inmediatamente ese mismo acto de existir sin necesidad de la forma.

Del análisis hermenéutico de estos textos podemos sacar las siguientes conclusiones:

1. La materia posee dos actos: uno que le da el ser-en-acto; otro que le da el ser tal y tal. La materia existente en una sustancia específica, en el actual estado de cosas, ha sido afectada por dos actos distintos: a) por el acto en cuanto actualidad de ser, o existir por el que la materia, en cuanto esencia distinta de la forma, existe. Acto que proviene de Dios mediante la forma. b) por el acto formal, por el que la materia, juntamente con la forma, se constituye en una sustancia específica. Este acto de ser formal es la forma misma.

2. Esos dos actos son distintos por distintas razones: a) el acto, como actualidad de ser, hace que la materia, en cuanto esencia distinta de la forma exista en acto. La causa eficiente principal de ese acto de existir de la materia, es Dios aunque, en el presente estado de cosas, realice ese acto mediante la forma. Parece que la forma fuese con respecto a este acto de ser de la materia una simple causa instrumental y segunda. b) el acto formal perfecciona a la materia y la hace pertenecer a una sustancia específica. La forma es, en este caso, el acto mismo formal por la que la materia se constituye en parte esencial de una sustancia específica. Marston va a decir que podemos comparar la materia ya sea con la forma o con el Creador. La materia tiene de la forma el ser tal o tal, es decir, el ser específico. La materia tiene del Creador una esencia verdaderarnente distinta de la forma y, en consecuencia, por su esencia no es dependiente de la forma sino más bien del Creador. ${ }^{10}$

3. Dios, por no ser contradictorio y, por tanto, imposible, puede, en su omnipotencia divina, hacer que la materia exista sóla sin forma alguna. Pero no puede, por contradictorio e imposible, darle el acto formal a la materia sin la forma, de igual manera que no puede hacer una pared blanca sin blancura."

4. La materia, en el presente estado de cosas, posee una esencia propia a la que acompaña un acto de ser propio, que le es inmediato e inherente, causado por Dios y donado a la materia por medio de la forma. Este acto de ser propio de la esencia de la materia no es, en el presente estado de cosas, autónomo y suficiente sino que se encuentra subordinado y dependiente del acto formal causado por la forma. Este acto de ser propio de la materia, en cuanto esencia distinta de la forma, es el antecedente de las distintas realidades no autónomas que vamos a encontrar en distintos Franciscanos, especialmente en Duns Escoto.

He ahí la materia como realidad absoluta con una esencia y una existencia propias distintas de la forma. Existe, sin embargo, siempre en los individuos concretos o compuestos unida a la forma. Los individuos concretos, sustancias

10 Quodlibet $I V$, q. II, p. 369, 5: "materia autem potest comparari vel ad formam a qua habet esse tale vel tale; vel potest comparari ad suum Opificem, a quo habet essentiam vere distinctam a forma, utique per essentiam non dependentem a forma sed magis ab Opifice."

" Op. cit., p. 369, 5: "Dico igitur quod (si Deus) daret huic materiae esse idem numero quod habet vel habere potest $a b$ aliqua forma, hoc implicat contradictionem sicut faceret parietem albam sine albedine; et sic non potest facere materiam sine forma. si tamen essentiae materiae, quae non dependet a forma sed a suo causatore, daret esse actu sine forma ulla, nulla esset contradictio." 
primeras - compuestas de materia y forma - son y son tales por la forma. Por eso, en el orden natural existente la materia no se da sin la forma, ya que de ella recibe la perfección de ser en el compuesto o en la sustancia.

\section{2 - Dios puede crear la materia sóla, sin la forma}

Ferdinand Etzkorn, tratando de resumir la doctrina de Marston sobre la materia, dice que la materia es esencialmente distinta de la forma y posee una potencialidad a una existencia autónoma, separada de la forma. ${ }^{12}$ Lo que no descubre Etzkom es la causa ontológica de esa potencialidad de la materia. La materia de Marston encierra la potencia de una existencia autónoma separada de la forma que se origina precisamente en el acto-de-ser propio e inherente a la esencia misma de la materia y que es distinto, como ya hemos visto, del acto formal que da el ser tal y tal, es decir, la sutancia específica.

Dios, repetimos, no puede, por imposible y contradictorio, dar el acto formal a la materia para constituir una sustancia específica, sin la forma. Dios no puede dar el ser tal y tal, sin la forma. Pero puede, en su omnipotencia divina, cambiar el orden actual del universo y hacer que la materia exista sola separada de la forma. La forma no es el acto-de-ser propio de la materia y, por tanto, Dios puede, en otro orden, mantener la esencia de la materia en-acto o en su existencia sin la forma. La materia, como esencia distinta de la forma, conlleva su propio acto-de-ser o su propia existencia que, en el presente orden del universo, no es autónoma e independiente de la forma. Pero la omnipotencia divina, cambiando el presente orden, puede mantener la esencia de la materia en su existencia sin la forma.

Para Tomás de Aquino, 'la existencia de la materia sin la forma' era imposible por contradictorio, debido a que el acto-de-ser de la materia era la forma misma y, en ese caso, 'la existencia de la materia sin la forma' equivale a 'el acto-de-ser de la materia sin su acto-de-ser', lo cual es evidentemente contradictorio.

El mismo Tomás de Aquino va a explicar el acto milagroso que se produce en la Eucaristía por el que los accidentes continúan existiendo sin su sustancia o sujeto natural, afirmando que el accidente recibe el ser de la sustancia pero la sustancia no es el acto de ser del accidente. Y lo demarca y distingue del ser-enacto de la materia: el acto de existir de la materia es la misma forma. ${ }^{12}$ Por eso Dios puede en su omnipotencia divina conservar los accidentes sin su sustancia en la Eucaristía: porque el ser del accidente no es su sustancia, aunque provenga de ella. Pero no puede conservar ni crear la materia sin forma alguna.

Para Marston, por otro lado, la existencia de la materia se asemeja a la existencia de los accidentes en la Eucaristia. La materia recibe, en efecto, su actode-ser o su existencia de la forma, pero la forma no es su acto-de-ser, de manera semejante a como los accidentes reciben el acto-de-ser de la sustancia pero la sustancia no-es el acto de ser de los accidentes. En consecuencia, mientras para

12 Etzkom, F., "The Grades of the Form according Roger Marston OFM", p. 423: "it is essentially distinct from the form and has a potentiality to autonomous existence apart from the form."

13 Quodlibet I, q. I, p.10, No.3: "ipsum esse accidentis non est substantia, quamvis sit ab ea, sicut actus existendi materiae est ipsa forma." 
el Aquinate la existencia de la materia sin la forma es imposible por contradictorio, para Marston la existencia de la materia sin forma alguna es posible porque no encierra contradicción. Por eso, para Marston, Dios hace en la Eucaristía que "el accidente subsista sin su sujeto, pero no hace que el accidente sea sustancia porque la esencia del accidente es subsistir en la sustancia y de manera análoga cuando hace que la materia, que de suyo es en potencia, exista en acto no hace que la potencia sea acto, sino que aquello que de suyo es en potencia lo hace subsistir en acto por si mismo.""

Para Marston, la relación de la materia a su forma es semejante a la del accidente con su sustancia. ${ }^{\text {ib }}$ Por eso, Marston argumenta que si Dios puede mantener en el ser a un accidente sin convertirlo al mismo tiempo en sustancia, como sucede con los accidentes en la Eucaristía, con mayor razón puede mantener en el ser a la materia que de suyo es en potencia, sin la forma. Esto no significa que la potencia sea acto sino simplemente que aquello que de suyo es-en-potencia pueda subsistir en acto por sí mismo. La materia, en efecto, es, para Marston, una entidad absoluta, mientras que el accidente es siempre una entidad relativa y dependiente de su sustancia.

\section{3 - La materia prima no es sujeto de generación}

La tradición aristotélica había explicado los cambios sustanciales, recurriendo a la materia prima como sujeto de esos cambios. En efecto, el cambio de las formas sustanciales se producía teniendo como sujeto inmutable la materia prima, sobre la que el cambio se producía. La explicación de los cambios sustanciales exigia la necesidad de un sustrato informe e inmutable denominado materia prima sobre el que se daba el cambio sustancial de formas.

Rogerio Marston rompe con esta tradición aristotélica para sostener de una manera tajante que "la materia prima, sin estar acompañada de forma alguna no puede ser sujeto de generación", "materia prima, omni forma circumscripta, subjectum generationis esse non potest". El sujeto de toda generación es, para Marston, un sujeto sustancial genérico, común a las formas que cambian. ${ }^{16}$ E1 sujeto de cambio sustancial debe ser un compuesto de materia y una forma genérica, que sea común a las dos formas: a la vieja que se corrompe y a la nueva que se manifiesta en la nueva sustancia." En concreto, Marston afirma que el sujeto de generación debe ser algo corpóreo, de manera que la corrupción de la forma se produzca sobre algo formal existente en la materia, o sea, sobre la corporeidad de la materia.

" Marston, Quodlibet I, q. II, p. 11-12: "Unde sicut quando Deus facit accidens subsistere sine subiecto, non tamen facit quod sit substantia quia semper natum est in substantia subsistere, sic quando fac it materiam, quae de se est in potentia, actu existere, non facit potentiam esse actum, sed illud quod de se est in potentia facit actu subsistere per se ipsum." Op. cit., p. 11, 6: "esse materiae de se est in potentia sicut accidentis esse est inesse."

${ }^{16}$ Op. cit., q. XV, p. 45, 7: “[...] materia prima, omni forma circumscripta, subiectum generationis esse non potest, sed ipsa materia sub forma corporeitatis et potentiis activis [...]."

"Quodlibet I, Q. XV, p. 41, 6, b: "Ita dico quod subiectum generationis non est quantum, hoc est dicere sub ratione qua quantum est, non subicitur, sed sub ratione qua est quid vel substantia." 
Hemos de tener en cuenta que, para Marston, generación es entendida en un sentido amplio semejante al concepto aristotélico de cambio; por eso, define generación como "eductio alicuius de potentia in actum", pasar algo de potencia a acto. ${ }^{18}$ Este paso supone en consecuencia, un termino a quo y un término ad quem; el término ad quem se encuentra en potencia en el término a quo. Ahora bien, la generación por excelencia es la generación sustancial o el cambio sustancial, por el que una sustancia individual se transforma en otra distinta. El indivíduo sustancial producido en la generación se encontraba ya en potencia en el individuo sustancial a partir del que, a quo, se produce la generación sustancial. Marston llama la atención para no confundir generación en su sentido fuerte de cambio sustancial con movimiento o cambio de lugar: el sujeto del movimiento es un ente en acto capaz de subsistir per se, mientras que el sujeto de la generación es un ente en potencia, de ninguna manera capacitado para subsistir a no ser con las otras formas inducidas sobre ese sujeto. ${ }^{19}$ E1 sujeto del cambio de lugar es un individuo sustancial subsistente en acto; el sujeto de la generación es una sustancia con una materia y una forma genérica, común a los dos términos de la generación, pero, por genérico, no puede subsistir en acto.

Distintas razones aporta Marston para sostener su tesis de que el sujeto último de generación debe ser una materia corpórea; pero podriamos resumirlas en las siguientes: a) la diferencia esencial existente entre forma y materia hace imposible que la forma pueda corromperse en la materia o viceversa. Materia y forma, como principios absolutos de la sustancia, no pueden el uno resolverse en el otro, ni del uno generarse el otro. Por eso, la forma ha de resolverse sobre algo formal, genérico, pero formal; ${ }^{\infty}$ b) si las formas se corrompiesen siempre en la materia prima, no podría explicarse por qué se genera una forma y no otra distinta; cualquier forma podría producirse a partir de algo tan indeterminado como la materia prima. $^{21}$

El sujeto de generación debe ser, por tanto, algo compuesto de materia y forma, para que la nueva forma se origine a partir de algo formal y la nueva materia a partir del elemento material, pero ese compuesto ha de ser lo suficientemente genérico como para poder servir de puente entre las dos sustancias trasmutantes. ${ }^{p}$

La acción natural no se produce sobre algo indivisible, sino que tiene que darse sobre cuerpos, y, por eso, toda forma se resuelve y se produce a partir de un

\footnotetext{
Op. cit., p. $41,6 \mathrm{~b}, \mathrm{v} .12$.
}

1 Quodlibet I, q. XVII, p. 5 1, c: “[...] quod tunc generatio esset motus, patet quod non valet, quia motus requirit subiectum ens actu potens per se subsistere, sicut patet [...]. Subiectum vero generationis est ens in potentia, nullo modo natum subsistere nisi superinductis aliis formis."

» Quodlibet II, q. XXII, p. 232, contra: "forma naturalis est aliqua essentia et substantia, et vere differens vel distincta a materia. Sed non est aliquid de quo ipsa fiat, quia non de essentia materiae. Non enim potest essentia materiae transire in essentiam formae per operationem naturae."

21 Quodlibet I, q. XV, p. 44, f: "si enim in omni transmutatione substantiali fieret resolutio usque ad materiam primam omnino sine forma, ita cito fieret sanguis de aceto vel de aqua sicut de vino maracemino, et ita faciliter caro de rapa sicut de perdice, quod nullus dubitat esse falsum."

n Op. cit., p. 37, 4, a: "oportet quod subiectum utriusque contrariorum sit ex materia et forma compositum." 
sujeto corpóreo sin que éste pueda resolverse en su materia y su forma en el actual orden de naturaleza. ${ }^{2}$

Los cambios sustanciales se manifiestan continuamente en la naturaleza y se producen por la acción de agentes naturales que hacen que una sustancia se transmute en otra especificamente distinta, v.g. el agua, al evaporarse, se transmuta en aire o el madero se transmuta en cenizas. El sujeto de esa transmutación sustancial debe ser, en ambos casos, algo genérico, común a ambas especies - agua, aire, madera y ceniza -, es decir, tiene que ser algo corpóreo o una materia con la forma de cuerpo. La forma de agua se corrompe en algo corpóreo de donde se extrae, por medio de un agente natural, la forma de aire.

Hemos de advertir que, para Marston, la transmutación sustancial se da en todo el compuesto de materia y forma, es decir, en toda la sustancia individual. Por eso, los cambios sustanciales encierran no sólo un cambio sustancial de la forma sino también un cambio sustancial en la materia. "Generatio est mutatio totius in totum; ergo nulla forma manet. Nec est instantia de materia, quia licet ipsa maneat secundum essentiam, corrumpitur tamen et generatur secundum esse [...]"." El hecho de que en la generación se produzca una mutación de todo en todo, no significa que no permanezca nada común. Simplemente quiere decir que el proceso de transmutación afecta a toda la sustancia, es decir, al ser sustancial de la forma y también el ser sustancial de la materia; y el sujeto de esa transmutación, es decir, el sujeto en el que se resuelve el viejo ser sustancial tanto de la materia como de la forma y a partir del que se genera el nuevo ser sustancial de la materia y la forma es algo corpóreo, una sustancia corpórea. ${ }^{\text {× }} \mathrm{La}$ transmutación de la sustancia se produce originada por un agente externo que activa el cambio de forma específica y, por tanto, del ser sustancial por el que una sustancia se constituye como tal sustancia. Ser sustancial o formal que, como antes dijimos, perfecciona a la materia, le da el ser tal y la constituye en elemento de una sustancia concreta. El viejo ser sustancial desaparece, y con él la vieja forma y, a la vez, la materia pierde ese ser sustancial por el que pertenecía como elemento constituyente a esa sustancia concreta. El ser sustancial o formal de la materia desaparece con la vieja forma. Una materia, con un ser formal o sustancial especificamente distinto, se va a producir con la nueva forma y la nueva sustancia, pero a partir de un sujeto sustancial común a ambos indivíduos sustanciales. Si, en las transmutaciones sustanciales, el ser de la forma desaparece para dar paso a otro nuevo ser formal, de igual manera, desaparece el ser formal de la materia - no el ser propio de la esencia de la materia - para dar paso a otro ser formal distinto del primero, por el que la materia se constituye en elemento de la nueva sustancia, "in generatione totum transmutatur, quia tan materia quam forma substantialiter transmutantur et totam in totam" (Quodlibet I, q. XV, p. 42, d).

3 Op. cit., p. 38, b: "necesse est tale subiectam corporeitatem habere, cum actio naturae non recipiatur in indivisibili."

${ }^{24}$ Op. cit., p. 39,5 , d.

` Op. cit., q. XV, p. 42, 6, d: "quando dicit quod generatio est transmutatio totius in totum, non est intelligendum quod nihil commume maneat, sed ipsum individuum generis utriusque speciei manet, quod est subjectum, quia substantialiter transmutatur, ut saepius dictam est." 
El sujeto último de generación es, como hemos dicho, una sustancia corpórea. El paso sustancial de agua a aire tiene como sujeto una sustancia corpórea genérica común al agua y al aire. En la medida en que la generación se produce entre indivíduos sustanciales más perfectos, el sujeto de generación será, a su vez, más perfecto, pero siempre común a ambos términos de la generación, al término a quo y al término ad quem. La generación en las especies superiores como los animales, por ejemplo, la generación de un asno, ha de entenderse como el tránsito sustancial de una sustancia de asno A a otra sustancia de asno B. El sujeto de tal generación debe ser una sustancia corpórea, viviente, animal, común a ambos indivíduos, en la que se resuelve el ser sustancial de A y a partir de la que se origina la sustancia $B$.

Para finalizar, hemos de recordar que tal sujeto de generación, o sustancia corpórea compuesta de materia y forma genérica no existe en acto. Las formas genéricas e, incluso las específicas, si no se individualizan, no pueden existir. ${ }^{{ }^{5}}$ En acto, en efecto, existen sólo los indivíduos pertenecientes a una especie concreta. Sin embargo, parece tener alguna suerte de realidad con la que se constituye en sustancia corpórea y genérica, que encierra potencialmente los futuros seres especíicos que de ella se derivarán en un proceso de perfeccionamiento. No llega, por supilesto, esta realidad a ser un indivíduo con capacidad autónoma de existir. Nos parece vislumbrar en este sujeto de generación de Marston un lejano bosquejo de la futura naturaleza común escotista.

Digamos dos palabras sobre la relación de la materia con el accidente cantidad. La materia con su realidad absoluta es el fundamento tanto de la sustancia como de la cantidad. La sustancia y la cantidad se constituyen juntamente cuando la materia recibe la forma especifica. Pero Rogerio Marston distingue entre "partes sustanciales de la materia" y "partes cuantitativas de la materia". Las partes cuantitativas que suponen una extensión con límites determinados le advienen a la materia con la forma específica y constituyen el accidente cantidad. Pero las partes sustanciales parecen pertenecer a la materia, incluso antes de recibir la forma, ya que existen distintas en la materia por medio de sus esencias. Para que no quede duda de que la materia encierra en sí misma las partes sustanciales que nada tienen que ver con el accidente de cantidad extensiva, Marston sostiene la hipótesis de que si por la divina potencia fuera eliminada del mundo toda cantidad, la materia conservaria sus partes distintas en el orden esencial y las conservaria separadas unas de otras y la materia tendría

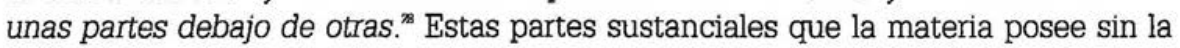
forma parecen identificarse con las dimensiones indeterminadas de las que habla

* Quodlibet I, q. XV, p. 45, 8: "Unde tale subjectum generationis non dicitur ens actu, quamvis habeat aliquam formam, quia, secundum tale, non potest actualiter existere."

zl Quodlibet II, q. 29, p. 291, No. 4a: "quae tamen materia partes habet substantiales et quantitativas."

* Op. cit., p. 292, No. 4a: "Partes ergo sustantiales materiae sunt in ea per suas essentias distinctae. Unde, omni quantitate a mundo substracta per divinam potentiam, remaneret materia cum suis partibus ordine essentiali distinctis, sicut modo videamos remanere ipsas ab invicem separatas, et haberet materia partes suas infra partes." 
Averroes y que preceden a toda forma sustancial. ${ }^{x}$ Dimensiones indeterminadas 0 posibles que se tornarán determinadas y concretas en el momento que el sujeto de generación reciba la forma sustancial y, con ella, el accidente cantidad con todas sus determinaciones.

\section{4 - Doble función de la potencia receptiva de la materia}

En la naturaleza, desde el momento mismo de la creación, se da un proceso ininterrumpido de cambios sustanciales en los que una forma sustancial se corrompe en el sujeto corpóreo para, de allí, generarse otra forma sustancial nueva y especificamente distinta de la primera. La materia, como parte constitutiva del compuesto o del indivíduo concreto, también sufre un cambio en su ser sustancial semejante al de la forma, corrompiéndose el ser sustancial de la vieja materia para engendrarse una nueva materia a partir del nuevo ser sustancial. Para explicar este proceso de cambios en la materia, Rogerio Marston va a asignar a la potencia receptiva de la materia una doble función: una función receptiva o pasiva y otra función de alguna manera positiva 0 activa. ${ }^{x}$ Por la función pasiva o receptiva, la materia posee la disposición de recibir infinitas formas, no simultaneamente sino sucesivamente. ${ }^{11}$ Por la función positiva o activa, la materia encierra en sí misma la capacidad de, en cada cambio sustancial, transmutarse sustancialmente para ajustarse y corresponder a la nueva forma sustancial con la que constituye un nuevo compuesto o una nueva sustancia individual. La materia, dice Marston, responde a la forma, "esse materiae correspondet substantialibus esse ipsius formae” (Quodlibet I, q. XVII, p. 270, e). La función activa de la materia de alguna manera se enraiza en la potencia receptiva de la materia, por la que possee la disposición de recibir formas y, con ella, los seres sustanciales que de ella derivan.

Expliquemos esta función activa de la materia, que pertenece a la sustancia misma de la materia y es distinta de la potencia - también activa de la materia pero no esencial - de la que se generan las diversas formas. Marston explica la generación de toda sustancia natural a partir de una forma diminuta oculta en la materia, la cual, por un proceso sucesivo de transmutaciones, va a ir perfeccionándose hasta alcanzar la plenitud del ser como indivíduo de una especie concreta. Este proceso de desarrollo y perfeccionamiento de las formas disminuídas, lo veremos más tarde, al hablar de las razones seminales. Lo que está claro, para Marston, es que a un perfeccionamiento y ennoblecimiento de la forma por medio de transmutaciones sucesivas, debe corresponder paralelamente un perfeccionamiento y un desarrollo de la materia. La materia, igual que la forma, posee la potencia de pasar de una materia menos completa a otra más completa.

Fijémonos un momento en este texto citado:

* Op. cit., p. 292, No. 4b: “et has partes infra partes, credo quod vocat Commentator [...] dimensiones indeterminatas quae praecedunt formam substantialem in materia."

* Quodlibet II, q. XXII, p. 258, b: "A parte vero potentiae receptivae que est in materia, convenit intelligere quandam potentiam quodam modo activam et quodam modo receptivam: unde non tantum receptiva et passiva, sed aliqualiter activa."

${ }^{3}$ De Anima, q. V, p. 325, 9: "[...] materia nunquam habet formas infinitas in actu et simul, sed potentia et sucessive." 
"la sustancia de la materia nació para ser llevada del ser incompleto a otro más completo sin recibir el ser más completo de afuera. De aquí que de alguna manera este ser que estaba latente en ella, adquiere un ser más noble por medio de un agente extrinseco".

Descompongamos este párrafo en proposiciones:

1. La sustancia de la materia nació para ser llevada de un ser incompleto a otro más completo.

2. Este ser más completo no lo recibe de afuera.

3. El ser que estaba latente en la materia adquiere un ser más noble por medio de un agente extrínseco.

Es consustancial a la materia esta potencia de pasar de un ser incompleto a otro ser más completo y, como hemos dicho, se enraíza en la misma potencia receptiva de la materia. El ser más completo no lo recibe de afuera sino que estaba de alguna manera latente en la materia. Y para que ese ser latente en la materia adquiera un ser más noble, se precisa un agente extrínseco que actúe sobre dicha materia. El agente extrínseco actúa sobre la sustancia individual existente con el fin de transmutarla, y esta acción afecta por igual a las dos partes constitutivas de esa sustancia, a saber, la forma y la materia. Ambas, forma y materia, poseen por igual la potencia de perfeccionar su ser, de ennoblecerlo, desarrollando seres ocultos o latentes encerrados potencialmente en cada una de ellas. Marston afirma que esta potencia perfeccionadora de la materia podemos considerarla activa no por la capacidad de actuar sino por la actualidad de ser. ${ }^{33}$ Pero esta potencia activa y perfeccionadora de la materia es muy distinta de la potencia activa de la forma

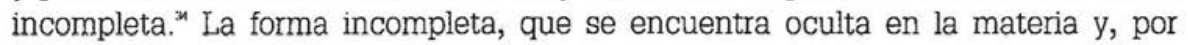
eso, se llama su potencia activa o razón seminal, tendrá su propio proceso de desarrollo, tal como lo veremos más tarde. La potencia perfeccionadora de la materia, de alguna manera, está subordinada a la forma que va a recibir y se perfecciona o ennoblece precisamente para poder recibir una forma más noble o perfecta.

La materia sigue, igual que la forma, un proceso por el que se va perfeccionando hasta alcanzar las últimas especies especialísimas como son el ser humano, un caballo o un asno. La materia de este caballo o de Pedro es, para Marston, mucho más perfecta y más noble que la materia del agua o del aire de igual manera que lo es la forma correspondiente. Este proceso de perfeccionamiento se realiza por medio de múltiples transmutaciones que hacen que una substancia genéricamente corpórea como una piedra se vaya transformando en indivíduos específicos cada vez menos genéricos, a saber, un vegetal, un animal y finalmente un caballo. La constitución esencial de la materia

3 Op. cit., p. 258, b: “[materia] est enim incompleta respectu esse completioris ipsius materiae: est enim substantia materiae nata ut deducatur ab esse incompleto ad completius absque receptione esse completioris ab extra. Unde quodam modo istud esse quod latebat in ea, per agens extrinsecum acquirit esse nobilius."

3 Op. cit., p. 259, c: "Et potest haec potentia aliquo modo dici activa, non ab activitate sive potestate agendi, sed ab actualitate essendi."

is Op. cit., p. 258-259, c: "[...] tamen magna differentia est inter hanc potentiam activam quae est formae incompletae et potentiam quae se tenet ex parte materiae." 
y sus disposiciones irán cambiando de acuerdo a la forma correspondiente que va a recibir, de manera que la constitución esencial y sus disposiciones irán ennobleciéndose y perfeccionándose correlativamente a la forma que va a recibir para constituir un individuo sustancial. La materia de caballo posee una perfección mucho mayor que la materia de aire o de piedra, perfección que se debe a la esencia de la materia que ha venido perfeccionándose y actualizándose a través de las sucesivas transmutaciones. Esta materia posee una sola y única esencia más noble, sin duda que la que poseía la materia prima. Y esta mayor nobleza y perfección de esta materia de caballo se debe a los múltiples y diversos seres substanciales que encierra. En efecto, igual que la forma, la materia de una especie especialísima, v.g. de caballo, encierra los múltiples y diversos seres sustanciales de las especies y géneros subalternos. La materia de caballo, con una única esencia, posee sin embargo los seres sustanciales de sustancia, de mixto, de vegetal, de animal y, por supuesto, de caballo.

En toda generación o transmutación es preciso que cambien sustancialmente tanto la materia como la forma, en el sentido de que ambas recibirán nuevos seres sustanciales, lo que entraña una transmutación sustancial. La materia, en cada transmutación específica, adquiere un nuevo ser sustancial, sin que eso signifique la pérdida de los seres sustanciales anteriores. Existe en la materia una potencia activa que la posibilita para transmutarse y adquirir nuevos seres sustanciales en un proceso semejante al que sigue la forma a partir de las razones seminales. Por tanto, en la transmutación sustancial de un compuesto la materia A cambia en sus seres sustanciales, "in suis esse substantialibus" y se transmuta en la materia B, preparándose de esa forma para recibir la nueva forma B. Sin este cambio en los seres sustanciales de la materia, producido por esa función activa de que estamos hablando, no podría producirse el cambio sustancial de la forma, pues la nueva forma no puede inducirse en la materia, si ésta mantiene el ser sustancial para la forma anterior. ${ }^{36}$ Por eso, el agente natural, origen de la transmutación sustancial del compuesto, sin necesidad de corromper el ser primero de la materia le induce un nuevo ser que conlleva nuevas disposiciones que preparan la inducción de un nuevo ser de la forma. Y este cambio en el ser sustancial de la materia y sus disposiciones precede al menos logicamente a la nueva forma, "concedo igitur quod in materia praecedunt dispositiones ad formam".

Y añade: esta potencia...tiende a seres distintos y propios de la misma materia de acuerdo a las exigencias de las formas que se engendran en ella. La materia de Pedro, por ejemplo, será la materia prima perfeccionada por los seres sustanciales sucesivos, recibidos en el largo proceso de pasar de un ser elemental, el agua, a un ser vegetativo en primer lugar, a un ser sensible o animado en segundo lugar y, finalmente, a un ser humano concreto llamado Pedro. Y cada ser sustancial añadido al anterior no sólo no anula o corrompe al anterior sino que lo

Quodlibet I, q. XVII, p. 53, 6: "nova forma non potest induci in materiam stante dispositione materiae quam habuit ad priorem formam, ideo agens ex intentione destruit primum esse materiae et inducit novum per eiusdem substantialem transmutationem. Concedo igitur quod in materia praecedunt dispositiones ad formam." 
completa y lo perfecciona. ${ }^{x}$ El indivíduo de una especie se produce, para Rogerio Marston, a partir del sujeto de generación que, como hemos dicho, es una materia corpórea genérica, al que se le van añadiendo seres sustanciales distintos hasta alcanzar el último ser específico del indivíduo. Todo indivíduo o sustancia individual no tiene sino una sola forma y una sola materia pero ambas tendrán diversos seres sustanciales que las han ido perfeccionando paulatinamente hasta terminar por hacerlas pertenecer a una especie concreta y constituyendo un indivíduo. Pedro es un compuesto de una sola materia o cuerpo humano y una sola forma o alma racional; pero tanto la forma racional como el cuerpo humano tendrán varios y diversos seres sustanciales que hacen que este participe de los distintos géneros y especies subalternos. Es decir, el cuerpo de Pedro - igual que su alma racional - posee los diversos seres sustanciales que la hacen ser materia de una sustancia, de vegetal, de animal y de ser humano."

¡Cuán lejos está esta materia de Marston de la materia aristotélicotomista a la que se opone! De potencia pura, sin ni siquiera ser, pero tampoco sin ser nada, ha pasado a una entidad absoluta con esencia y existencia propias; y con una esencia y existencia tales que encierran una multiplicidad de seres, al principio en potencia, que llegarán a convertirse en acto, cuando las circunstancias lo exijan. La materia de Rogerio Marston no sólo posee un ser propio que le da la actualidad de existir sino que encierra también un ser con capacidad de expandirse, de completarse y de perfeccionarse con diversos seres que, al inicio, se encuentran en potencia pero en el transcurso del tiempo se actualizarán. Esta materia encierra en sus entrañas su propio desarrollo futuro, que se manifestará en seres materiales distintos de acuerdo a las distintas formas que vaya recibiendo.

\section{4 - Razones seminales}

Rogerio Marston habla en algunas ocasiones de potencia activa de la materia, refiriéndose a las razones seminales. Como formas incompletas, las razones seminales se encuentran ocultas en la materia, esperando el momento en que un agente externo las active para pasar a ser formas en acto y lograr así su total desarrollo. Todas las operaciones naturales van a ser explicadas por Marston a través de las razones seminales o formas incompletas o diminutas que fueron introducidas por Dios en la materia antes de todo tiempo. ${ }^{x}$ Siguiendo a Agustín, Marston opina que Dios creó todas las cosas de una vez en la materia prima en sus razones seminales. Este fue el verdadero momento de la creación en el que

\% Quodlibet I, q.XVII, p. 50,3: "materia sub forma generis generalissimi habet esse incompletissimum correspondens formae generis, quod tamen per actionem agentis promovetur et magnificatur continue per esse substantialia formae manentis, ita quod, adveniente posteriori, non corrumpitur esse quod prius erat, sed magis perficitur."

3/ Quodlibet II, q. XXII, p. 255, b: "nec pono hic plures formas, sed unam tantam habentem diversa esse substantialia quae per transmutationem acquiruntur." P. 256, c: "necesse est ponere transmutationem in ipsa substantia materiae correspondentem diversis esse substantialibus ipsius formae. Sicut enim esse nobilius habet forma in animali quam in mixto, sic etiam necesse est quod materia nobilius esse acquirat quia propriae formae respondet propria materia."

3 Quodlibet II, q. XXII, p. 246, e: "illae proprie vocantur rationes seminales quas Deus indidit materiae ante omnem diem, et secundum eas fiunt omnes operationes naturales usque modo." 
Dios creó todas las cosas potencialmente en la materia prima antes de todo tiempo. A partir de esas razones seminales o formas incompletas, se fueron produciendo todas las cosas en sus formas, sin que Dios haya vuelto a crear nada nuevo, ni siquiera nuevas formas seminales. La producción de los seres completos a través del tiempo es el momento que Marston, siguiendo a Agustin, llama obra de distinción por la que Dios distingue, actualiza y perfecciona los seres que se encuentran potencialmente insertos en la materia. ${ }^{*}$

Las razones seminales son consideradas por Marston como formas incompletas o diminutas, a las que Dios solo introdujo en la materia y sobre las que solamente Dios puede actuar para completarlas y perfeccionarlas. ${ }^{10}$ Ninguna criatura tiene poder alguno sobre las razones seminales y la acción de Dios sobre ellas se concreta a través de las leyes de la naturaleza. Ni siquiera el demonio puede actuar sobre las razones seminales para lograr que su ser potencial se complete y se actualice.

Marston concibe el universo como una realidad en contínuo proceso de cambio, de expansión y de perfeccionamiento a partir de la materia primigenia y corpórea en la que las razones seminales fueron creadas e introducidas por Dios. Ese cambio, expansión y perfeccionamiento se da a través de las leyes de la naturaleza que se manifiestan a través de los distintos agentes naturales. Estos actúan sobre las razones seminales haciendo que los múltiples seres sustanciales, que cada forma seminal o forma diminuta encierra, se vayan desplegando en el tiempo hasta lograr su total desarrollo y perfección. Ejemplo de este proceso evolutivo lo da Marston, cuando dice que en los seres naturales las formas de las especies se encuentran potencialmente en la forma más común o genérica y el proceso de generación procede la siguiente manera: en la forma de substancia está encerrada potencialmente la forma de corporeidad, la forma de mixto está potencialmente en la corporeidad, la forma animal en la forma de mixto y el caballo está en potencia en la animalidad." Es decir, que el desarrollo en el universo se realiza, partiendo de lo más genérico y material como es la forma de sustancia hasta terminar en la forma más concreta y perfecta - en este caso la de caballo - a través de los distintos pasos necesarios para que el total desarrollo de la forma inicial se produzca. Y la forma más perfecta, como en este caso la de caballo, se encuentra potencial pero esencialmente en la razón seminal originaria

* Quodlibet II, Q. XXII, p. 245, c: "Deus primo creavit omnia in materia prima in suis rationibus seminalibus, quae postea per opus distinctionis produxit Deus de ipsis rationibus seminalibus in materia inditis [...]. Deus autem nihil creavit novum, sed quia omnia facta sunt in rationibus seminalibus, ideo de ipsis omnia producendo per opus distinctionis nihil fecit novum, sed hoc tantum quod erat in potentia materiae produxit in actum."

* Op. cit., p. 247, g: "Quare contra intentionem Augustini sunt omnia dicta supra de rationibus seminalibus, scilicet quod sunt virtutes immissae ab agentibus perfectis, cum solus Deus super eas habet potestatem."

" Op. cit., p. 255, a: "in esse naturali formae specierum sunt in potentia in forma communiori. Sic ergo processus generationis fit per hunc modum: ut forma substantiae sit in potentia forma corporeitatis, et corporeitas forma mixti, et haec forma animalis, et haec forma equi." 
de la que procede; las razones seminales son algo de la esencia de lo producido mismo, afirma textualmente Marston. ${ }^{22}$

Entre la materia y la forma existe una proporción directamente proporcional a saber: a una forma más perfecta y más simple responde a su vez una materia más sutil y más perfecta. Cuanto más perfecta y simple sea la forma más virtud tiene y menos material es, mientras que cuando la forma es menos simple y, por tanto, más genérica exige una materia más primitiva y más densa. Marston expresa esta relación materia/forma, diciendo expresivamente "donde hay más materia allí hay menos forma y viceversa", ubi plurimum est de materia, ibi minus est de forma et $e$ converso, y pone como ejemplos, tomándolos de Arsitóteles, los elementos, que poseen más materia que la carne y el hueso y la carne y el hueso poseen más materia que la mano y el pie, y viceversa con respecto a la forma. ${ }^{*}$

Las razones seminales constituyen el elemento formal primigenio, introducido por Dios en la potencia receptiva de la materia. Y el universo se desplegará en un proceso de perfeccionamiento progresivo, en el que las razones seminales irán pasando de sus seres potenciales a formas actuales cada vez más concretas y perfectas y, a su vez, la materia irá respondiendo a este prefeccionamiento de la forma con su propio perfeccionamiento de acuerdo a esa potencia activa esencial de la materia, de la que ya hemos hablado. A partir de las sustancias corpóreas más genéricas, se irán produciendo sustancias menos genéricas y, cada vez, más específicas hasta alcanzar la especie especialísima del ser humano concreto o del caballo concreto. Y ese perfeccionamiento progresivo se da, siguiendo las leyes de la naturaleza y motivado por los agentes naturales que actúan sobre las substancias compuestas de materia y forma. En cada individuo de una especie especialísima nueva, v.g. un caballo, no es necesario poner varias formas ordenadas de la más genérica a la más específica; Marston dice tajantemente que en un indivíduo no hay más que una sola forma, la específica, en este caso la forma de caballo. Pero ella encierra distintos y múltiples seres sustanciales que explican las distintas transmutaciones subalternas que la forma originaria o corpórea fue sufriendo hasta alcanzar la perfección que hoy tiene, a saber, la forma de equinidad. Este caballo, en consecuencia, tiene, según Marston, sólo la forma de equinidad pero con los seres sustanciales de sustancia, de mixto, de viviente, de animal y, por supuesto, de caballo." Este proceso de estrechamiento de lo genérico a lo específico entraña una acumulación de distintos y múltiples seres sustanciales así como un perfeccionamiento o enuoblecimiento sucesivo de la forma que la va convirtiendo en más sutil y exigiendo una materia correlativamente más perfecta.

12 Op. cit., p. 245, c: "[...] necessario sequitur quod rationes seminales sunt aliquid de essentia ipsius producti."

* Quodlibet II, q. XXI, p. 256, b: "Et exemplificat quod elementa plus habent de materia quam caro et os, et caro et os plus de materia quam manus et pes, et e converso de forma."

* Op. cit., p. 255-256, b: "Nec tamen pono hic plures formas, sed unam tantam habentem diversa esse substantialia quae per transmutationem acquiruntur [...] dico quod non sunt in equo vel in asino plures formas, sed una habens diversa esse substantialia a quibus denominantur genera subalterna." 
Ese perfeccionamiento o paso de la razón seminal a formas completas puede realizarse milagrosamente en casos excepcionales y por intervención de Dios. Marston habla de una doble manera de actuar Dios milagrosamente: produciendo a partir de una razón seminal un efecto súbitamente cuando la naturaleza lo hubiera hecho en forma sucesiva; o bien, produciendo un efecto a partir de la materia pero sin la razón seminal correspondiente. En este útimo caso, v.g. cuando este ojo ciego ve o cuando un dedo perdido se restituye, el milagro se da debido a la potencia obediencial que la materia posee con respecto al Creador.

\section{3 - Conclusión}

Si volvemos la mirada atrás, nos daremos cuenta que la materia de Marston conserva rasgos fundamentales de la $v \lambda \eta$ (hýlê) aristotélica: forma parte del compuesto sustancial y se encuentra en potencia para recibir múltiples formas. Pero, como entidad propia, nos remite a la materia agustiniana, aquella materia que poseía en sí misma algún tipo de ser, ínfimo, expresado en frases como "nada algo", "ser que no es", "casi nada" (nihil aliquid, est non est, illud... prope nihil erat). Lo que ocurre es que la materia de Marston ha crecido hasta lograr cotas ontológicas insospechadas para el Obispo de Hipona. La materia de Marston está dotada de una esencia propia tan distinta de la forma que Marston afirma que se distingue más la esencia de la materia de la esencia de la forma que dos formas específicas. ${ }^{45} \mathrm{Y}$ esa esencia de la materia recibe en el compuesto sustancial un doble acto: un primer acto que le es inmediatamente inherente y que la hace ser-en-acto o existir, y un segundo acto formal que la hace pertenecer a una sustancia específica y ser tal y tal.

Ambos actos los recibe de la forma sustancial pero de muy distinta manera: el primer acto que sigue inmediatamente a la esencia y la hace ser-en-acto, la recibe de la forma pero la forma misma no es ese acto de ser; el segundo acto formal lo recibe también de la forma pero con el añadido de que la forma misma es el acto formal de la materia. La forma y el acto formal se identifican totalmente, según Marston, de manera que Dios no puede darle a la materia el acto formal sin la forma, ya que es imposible por contradictorio. Por el contrario, el acto que sigue inmediatamente y es inherente a la esencia de la materia, aunque lo recibe de la forma, se distingue de ella, de manera que puede suceder que la materia sea-enacto sin la forma en el supuesto de que Dios así lo quisiera, en otro orden de cosas. La relación de la materia a su forma es, para Marston, semejante a la existente entre el accidente y su sustancia: el accidente recibe el ser-en-acto de la sustancia pero la sustancia no es el ser del accidente. De aquí que si el accidente existe milagrosamente sin su sustancia, con mayor razón la materia encierra la posibilidad de existir en acto sin la forma, si la voluntad de Dios así lo dispone.

Esa esencia de la materia que es-en-acto posee la capacidad o disposición de recibir infinitas formas sucesivamente. Capacidad receptiva de formas que, a su vez, encierra la capacidad de desarrollarse, perfeccionarse y ennoblecerse en la

\footnotetext{
16 Quodlibet I, q. XV, p. 38, c: "cum corrumpitur aliqua forma, non corrumpitur in ipsam essentiam materiae, cum sint essentiae magis distinctae quam duae formae specificae."
} 
medida que lo exija la forma correspondiente que reciba. Ese desarrollo y perfeccionamiento se produce con el añadido de nuevos seres sustanciales correlativos a los nuevos seres sustanciales que la forma va a recibir posea. Es decir, esa esencia de la materia que es-en-acto encierra latente la potencia de su propio desarrollo, que se llevará a efecto en la medida que lo exijan las sucesivas formas que vaya recibiendo. La materia de Pedro, por ejemplo, es mucho más perfecta que la materia del agua o que la materia de un árbol; la materia de Pedro encierra en su ser cuerpo de Pedro los seres sustanciales de sustancia corpórea, de viviente, de animal y de hombre, de manera semejante a como la forma de Pedro encierra esos mismos seres sustanciales.

La entidad de la materia de Marston es mucho más crecida que la elaborada por Buenaventura: no posee esa misteriosa de ser algo absoluto y su relación, pero su ser absoluto, además de ser capacidad receptiva de infinitas formas, ha ađquirido la disposición activa, intrínseca y esencial, que la impulsa a progresar y a desarrollarse con nuevos seres sustanciales de acuerdo a las nuevas formas sustanciales que reciba.

La materia de Marston se asemeja más a la materia actual de su hermano en religion Ricardo de Mediavilla: ambas tienen esencia propia con su propio actode-ser que las hace existir y pueden ser creadas, separadas de la forma, por la potencia absoluta de Dios. Entre estas materias existen también marcadas diferencias: la materia de Ricardo de Mediavilla tiene su propio acto de ser, pero un acto de ser ínfimo que hace que su actualidad sea la más pequeña que podamos encontrar en los seres creados, "tenet tamen in entibus infimum actualitatis gradum" (Commentum super IV Sententiarum, lib. II, d. 12, a. 1, q-1, c (t. II, p. 143)) y su esencia continúa siendo infinita carencia o posibilidad de recibir formas sucesivamente. La materia de Marston con el acto-de-ser propio e inmediato de la esencia - no dice jamás que sea ínfimo - adquiere la doble función de recibir por un lado infinitas formas sucesivamente y por otro la capacidad de desarrollarse con nuevos seres sustanciales en un proceso de perfeccionamiento sucesivo. Por eso, mientras que la materia de Ricardo de Mediavilla es ingenerable e incomuptible, la de Marston, igual que la forma, transmuta sutancialmente en cada proceso de generación. La materia de Marston adquiere una realidad absoluta correlativa de la forma y con la propiedad análoga de encerrar, en su esencia, su propio desarrollo y perfección. Precisa sin embargo, en el presente orden de cosas, del acto formal para poder constituirse en una parte de un compuesto sustancial especifico que es el único que existe.

Finalmente las razones seminales de Marston, de onigen agustiniano, siguen las líneas maestras de Buenaventura: en efecto, las razones seminales van a explicar todo el desarrollo de la naturaleza o todas las trasmutaciones sustanciales que en el mundo sensible se producen. Las razones seminales son, en ambos autores, el elemento formal, introducido por Dios en la materia antes de todo tiempo, que se irá desarrollando y cambiando de su ser potencial a las formas completas distintas que, al correr del tiempo, se irán produciendo a partir de esas semillas. Para ambos autores es una potencia activa y determinada, especificamente perteneciente al mundo de las formas y distinta, esencial y realmente, de la materia, que 
necesita, sin embargo, de la acción de la naturaleza o de un agente natural externo para que esas semillas se desarrollen y se actualicen. Ricardo de Mediavilla, por otro lado, explicará el desarrollo de la naturaleza y sus trasmutaciones sustanciales por medio de la materia posible o materia capaz de trasmutarse en formas por medio de la acción del agente natural. Para Marston, esta concepción de Mediavilla seria incomprensible, debido a la enorme diferencia esencial existente entre la materia y la forma, que es mayor que la existente entre dos especies, y que imposibilita que la primera pueda trasmutarse en la segunda o viceversa.

En consecuencia, la materia, como parte del compuesto, ha alcanzado con Marston un enorme desarrollo muy superior a las materias que habían elaborado sus maestros franciscanos. No sólo posee una esencia y un acto-de-ser propios, sino que su misma esencia en acto encierra la capacidad de trasmutarse y de desarrollarse y perfeccionarse en la medida que lo vayan exigiendo las nuevas formas a recibir.

Esta materia crecida y con capacidad esencial para trasmutarse y completarse con diversos seres sustanciales no puede, sin embargo, ser sujeto de los cambios sustanciales o de la generación. Toda trasmutación implica la corrupción de la forma anterior en un sujeto y la generación de la nueva forma a partir de ese sujeto. La trasmutación sustancial, para Marston, implica la trasmutación sustancial del compuesto, es decir, de la forma y también de la materia, o sea, la corrupción de la vieja forma y de la vieja materia en un sujeto y, a partir de ese sujeto, la generación de una nueva forma y una nueva materia. Ese sujeto de generación tiene que ser, por tanto, un sujeto genérico compuesto de materia y forma, una sustancia corpórea: la forma se corrompe en la forma genérica de este sujeto y la materia se corrompe en la materia genérica de este sujeto que tiene la caracteristica de ser común tanto al término a quo como al término ad quem. En ese sujeto genérico de generación, se encuentra, en potencia, la nueva sustancia que se va a engendrar, es decir, el término ad quem. La nueva sustancia es el desarrollo o la perfección de ese sujeto genérico en el que se encuentran latentes $y$ en potencia tanto la nueva forma específica como la nueva materia correlativa a la forma. Y este sujeto genérico, aunque no puede existir en acto, autónomamente, precisamente por su ser genérico, sin embargo encierra alguna suerte de realidad, a partir de la cual el nuevo compuesto individual surge como su desarrollo y su plenitud.

La materia de Marston ha alcanzado un desarrollo ontológico que la hace correlativa y análoga con la forma en el ser-en-acto de su esencia. Un ser de la esencia que encierra en sí mismo, igual que la forma, todo su desarrollo futuro. 